\title{
TRACKING AND FORECASTING LOCAL ECONOMIC ACTIVITY
}

\author{
Claude Farrell and William W. Hall, Jr.*
}

Both the private and public sectors have a strong and growing interest in current and future economic activity at the sub-state or local level. Several factors are responsible for this interest but, perhaps, none more so than the decline, or stagnation, of certain real resource prices which occurred during the first half of the decade of the 1980s.

New Orleans, Louisiana, is an example of where this interest is readily apparent. As Conte (1986) points out, New Orleans is distinct from other parishes in Louisiana in that its economy is more dependent on port activity, tourism and offshore drilling. Offshore drilling has been dramatically reduced in the 1980 s as a result of the decline in crude oil prices. Prior to the early 1980s, the use of national indicators to forecast New Orleans employment was reasonably successful as the New Orleans business cycle closely paralleled the national cycle. However, over the first half of the 1980s, this symmetrical relationship has weakened as evidenced by the fact that while national employment grew by nine percent between December 1980 and December 1985, New Orleans employment declined by three percent. As a result, Conte concludes that "If we are to gain insight into the local economy, it has become necessary to develop forecasting instruments that do not 'piggy back' on national models.... Similarly, relying on a Louisiana state economic model is ... ill advised."

Conte's desire for the development of local indicators can be traced to the interdependencies in a local economy with which regional economists are familiar. When a major sector of a local economy contracts, there are ripple effects throughout the economy affecting numerous firms. In such instances, the ability of firms to acquire information on the current state of the local economy and its projected future level frequently makes the difference between bankruptcy and survival. Such information is also of great importance to local units of government in making reasonable projections of local tax revenues and public expenditures.

*The University of North Carolina at Wilmington. The authors wish to thank Ravija Badarinathi in the Cameron School of Business Administration at UNC-Wilmington for his help in developing the factor analysis model. The authors also wish to thank anonymous referees for their comments on earlier drafts of this article.
New Orleans could be considered as an extreme example of the need for local indicators. However, the currently depressed agricultural sector and the ongoing relocation of manufacturing from large metropolitan areas to smaller metropolitan and rural areas (Carlino, 1985, and Wheat, 1986) would provide other examples.

In contrast to New Orleans, many local economies are expanding, and some at a very rapid pace. One such area constitutes the data base for this article. The need for local indicators is equally important for these areas. For existing firms in these areas, the inability to anticipate growth means foregone opportunities and, perhaps, loss of market position to existing or new competing firms. In addition, firms contemplating the relocation of facilities out of declining and into growing areas could put this kind of information to advantage.

For local governments in growing areas, the ability to project the demand for public services such as roads, water supply, sewage disposal and education is of great importance in minimizing congestion, overcrowding and overloading and a subsequent breakdown of facilities. Local indicators can play a valuable role, as they have in the locality providing the data base for this article, in making such projections.

The first half of the decade of the 1980 s has also seen a shift in the responsibility for the delivery of many governmental services to the local and state levels. Nathan and Doolittle (1984) provide a brief synopsis of the budget cuts and the "New Federalism" programs of the first (1981-84) Reagan administration. This realignment has augmented the interest of public officials in local economic performance as, in these cases, they must assess the abilities of local and state governments to meet current and future demands for these services.

The purpose of this article is to provide some initial insight into a methodology for tracking, analyzing and forecasting economic activity at the local level. Such breadth of coverage has, and continues to be, available only at the national, and to a lesser extent, at the state level.

The geographic area for analysis is the Wilmington, North Carolina, area. The Wilmington area economy is composed of Brunswick and New Hanover Counties in the southeastern part of the state. The City of Wilmington serves as the service center for the area as all of the major regional shopping centers and regional centers for financial services are located within its confines. Wilmington 
is also a coastal city with a moderate climate and serves as a major tourism and retirement center. Although several major manufacturing firms have facilities in the area, the relative importance of manufacturing has decreased over the first half of the decade of the 1980s.

\section{Tracking Local Economic Activity}

A problem facing the regional economist is the lack of a satisfactory measure of overall economic activity in a small regional economy. The social accounting system necessary to construct gross regional product and related type measures is generally not available at the regional or local level. In addition, a multitude of economic, social and political factors within any region can influence its economy. A detailed list of these items would not only be lengthy but, at times, unwieldy and/or prohibitively expensive to measure. As a result, the regional economist is often required to rely on an index of some design as a surrogate measure of overall regional economic activity. In this section, the authors describe how both a coincident index and an index of leading economic indicators can be constructed for a local economy.

\section{Index Construction}

Approximately 15 monthly economic times series for the time period 1979-86 were compiled. During the data collection process, emphasis was placed on the reliability of the time series in terms of timing, smoothness, reasonable accuracy, i.e., not subject to drastic revisions, and proportionate coverage of the various economic processes within the local community (Zarnowitz and Boschan, 1975). Seasonality was removed from the data using the SAS (Statistical Analysis System) Census X-11 model. Correlation analysis was then performed to determine which of these variables were most highly related to seasonally adjusted total area employment. The variables so identified were seasonally adjusted air passenger traffic (passenger enplanements plus passenger deplanements) at the regional airport, seasonally adjusted area retail sales in constant (1967) dollars, seasonally adjusted area sales of electricity for commercial purposes, vehicle sales, the seasonally adjusted dollar value of total authorized building permits in constant (1967) dollars, seasonally adjusted area sales of electricity for industrial purposes and the seasonally adjusted national money supply, $M_{1}$ definition. The national money supply was used as a proxy for its regional counterpart because the state of North Carolina has the most liberal branch banking laws in the nation. As a result, deposit data by location is available only on an annual basis in the fall of the following year from the FDIC and the FSLIC. Thus, transactions deposit data by location is not available on a timely basis for the local area. Furthermore, arbitrage insures that it is inconsequential whether a national money supply figure or an interest rate figure is used as an appropriate proxy for the regional money supply. Sales of electricity for commercial and industrial purposes can be considered as proxies for commercial and industrial use of capital, respectively, because electricity is not storable at the user end.

In those cases where a measure of the total situation, in the present case gross regional or local economic production, is not available, factor analysis can be used to construct a composite index to reflect the current level of overall local economic activity and an index of local leading economic indicators. Following the procedure outlined by George (1980), factor analysis was used to combine or reduce variables which are linked to each other into indexes reflecting the basic structural features of the total situation being studied. Factor analysis was used first to determine which variables formed the leading index and which variables formed the coincident index. Factor loadings were then used to obtain weights for the variables in each index.

\section{A Local Coincident Business Index}

The Wilmington Area Business Index (WABIX) is the composite index of coincident indicators developed for the Wilmington area economy. The following four variables comprise WABIX: seasonally adjusted total area employment, seasonally adjusted retail sales in constant (1967) dollars, seasonally adjusted area sales of electricity for commercial purposes and seasonally adjusted passenger traffic at the New Hanover County regional airport.

As can be seen in the accompanying chart, WABIX was virtually flat during the six-month national recession which occurred during 1980 and the 18-month 1981-82 national recession. In addition, with a few exceptions, WABIX has historically decreased during the first and third quarters of the year and increased during the second and fourth quarters. Annual compound growth rates in local economic activity based on changes in WABIX between identical months in 1979 and 1986 have fluctuated between 4.2 and 5.3 percent with a mean of 4.9 percent and a standard deviation of 0.399 percent.

\section{A Local Index of Leading Economic Indicators}

The local index of leading economic indicators (LILE) is comprised of vehicle sales, seasonally adjusted area sales of electricity for industrial purposes, seasonally 

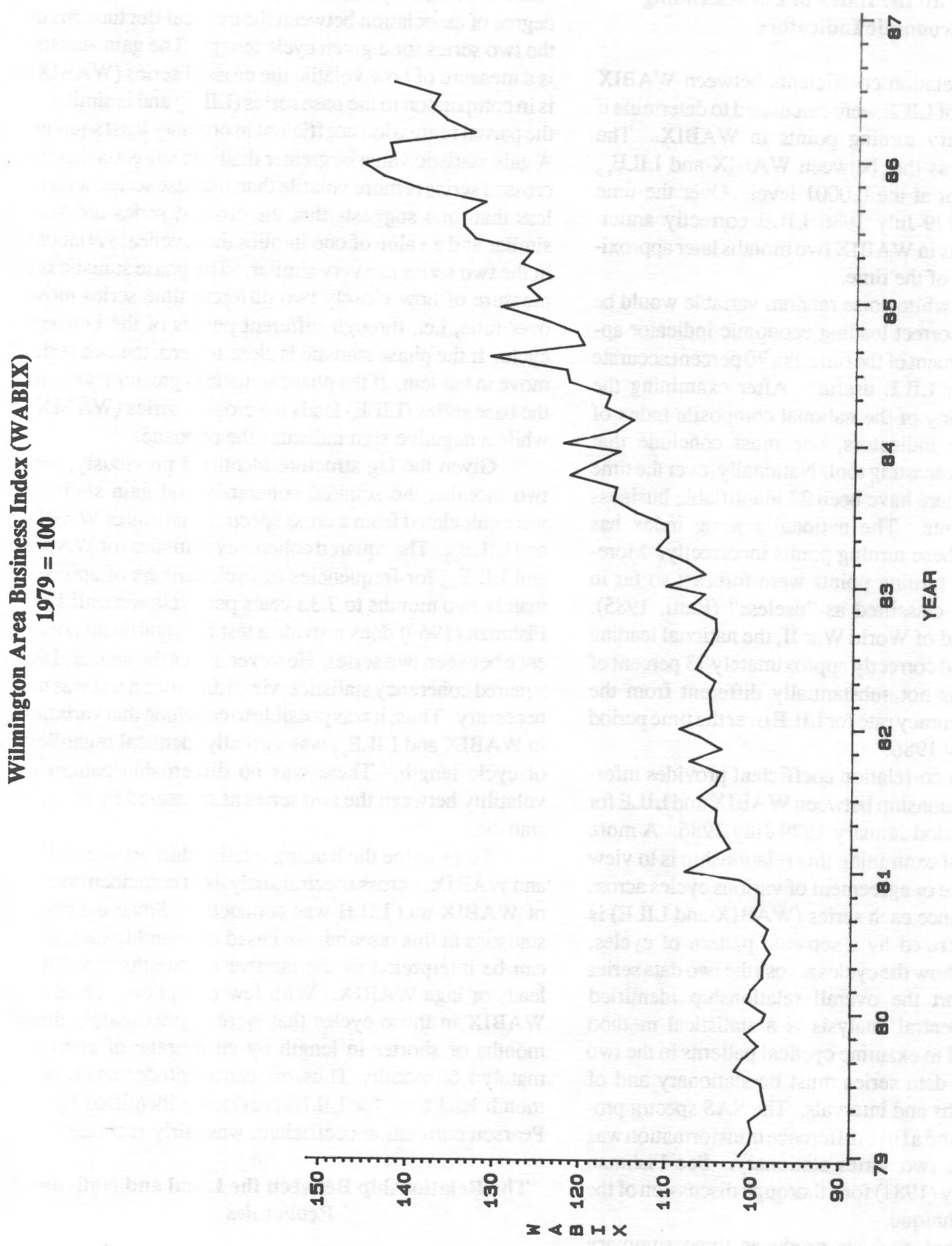
adjusted building permits in constant (1967) dollars and the seasonally adjusted national money supply $\left(M_{1}\right.$ definition).

\section{Forcasting With the Index of Local Leading Economic Indicators}

Pearson correlation coefficients between WABIX and lagged values of $L I L E$ were calculated to determine if LILE could identify turning points in WABIX. The largest $(0.8824)$ was that between WABIX and LILE and was significant at the 0.0001 level. Over the time period January 1979-July 1986 LILE correctly anticipated turning points in WABIX two months later approximately 70 percent of the time.

Given that a white noise random variable would be expected to be a correct leading economic indicator approximately 50 percent of the time, is a 70 percent accurate prediction rate for LILE useful? After examining the forecasting accuracy of the national composite index of leading economic indicators, one must conclude that LILE is a useful forecasting tool. Nationally, over the time period 1948-82, there have been 22 identifiable business cycle turning points. The national leading index has forecast three of these turning points incorrectly. Moreover, three of the turning points were forecast so far in advance as to be classified as "useless" (Ratti, 1985). Thus, since the end of World War II, the national leading index has predicted correctly approximately 73 percent of the time, which is not substantially different from the corresponding accuracy rate for LILE over the time period January 1979-July 1986.

The Pearson correlation coefficient provides information on the relationship between WABIX and LILE for the entire time period January 1979-July 1986. A more meaningful way of examining this relationship is to view it as the confluence or agreement of various cycles across the two series. Since each series (WABIX and LILE) is probably characterized by a separate pattern of cycles, there is interest in how the cycles across the two data series interact to support the overall relationship identified above. Cross spectral analysis is a statistical method which can be used to examine cyclical patterns in the two data series. The data series must be stationary and of comparable lengths and intervals. The SAS spectra procedure was used, and a first-difference transformation was used to make the two series stationary. See Fishman (1969) and Priestly (1981) for a thorough discussion of the cross spectral technique.

Cross spectral analysis produces three summary statistics that are of interest in this research effort. The squared coherency statistic provides a basis for inferring the extent to which the two series are correlated at each frequency or cycle length. As such, it is similar to the coefficient of determination $\left(R^{2}\right)$ in regression analysis and takes on values in the range 0 to 1 . The closer the squared coherency statistic is to one, the stronger is the degree of association between the cyclical fluctuations of the two series for a given cycle length. The gain statistic is a measure of how volatile the crossed series (WABIX) is in comparison to the base series (LILE) and is similar to the partial regression coefficient in ordinary least squares. A gain statistic value of greater than one suggests that the crossed series is more volatile than the base series, a value less than one suggests that the crossed series are very similar and a value of one implies that cyclical variations in the two series are very similar. The phase statistic is a measure of how closely two different time series move over time, i.e., through different phases of the business cycle. If the phase statistic is close to zero, the two series move in tandem. If the phase statistic is greater than zero, the base series (LILE) leads the crossed series (WABIX), while a negative sign indicates the opposite.

Given the lag structure identified previously, viz., two months, the squared coherency and gain statistics were calculated from a cross spectral analysis of WABIX and LILE $_{k-2^{\circ}}$ The squared coherency statistics for WABIX and $L I L E_{t-2}$ for frequencies or cycle lengths of approximately two months to 7.33 years per cycle were all 1.00 . Fishman (1969) does provide a test for significant coherence between two series. However, given the values of the squared coherency statistics, viz., 1.00 , such a test was not necessary. Thus, it was possible to conclude that variation in WABIX and $L_{I L E}$ was virtually identical regardless of cycle length. There was no discernable pattern in volatility between the two series as measured by the gain statistic.

To examine the leading relationship between LILE and WABIX, a cross spectral analysis of coincident values of WABIX and LILE was conducted. Since the phase statistics in this research are based on monthly data, they can be interpreted as the number of months that LILE leads or lags WABIX. With few exceptions, LILE led WABIX in those cycles that were approximately three months or shorter in length by an average of approximately 1.60 months. Thus, one can conclude that the twomonth lead time for LILE, previously identified by the Pearson correlation coefficient, was fairly accurate.

\section{The Relationship Between the Local and National Economies}

Do the local and national economies move in tandem? If so, then the use of national indicators to forecast 
local economic activity may be somewhat successful. As Conte (1986) emphasizes, to rely solely on such "piggy back" methods is hazardous. However, when used in conjunction with local leading indicators, "piggy backing" can be informative and, at times, useful. Of interest, then, is the relationship between local and national economic activity.

A search for national measures comparable to WABIX suggested the industrial production index prepared by the Board of Governors of the Federal Reserve System, the Business Week index prepared by McGrawHill, Inc., and the seasonally adjusted personal income series prepared by the U.S. Department of Commerce. The industrial production and Business Week indexes are heavily weighted by manufacturing. As stated previously, the relative importance of manufacturing in the Wilmington area economy has decreased since 1980 . Consequently, the authors selected the personal income series. This series was deflated with the CPI and indexed to the year 1979.

Based on data for the time period January 1979-July 1986, the Pearson correlation coefficient for coincident values of WABIX and the real personal income series index (RUSPI) was 0.9622 and significant at the 0.0001 level. These coefficients were also calculated for WABIX and lagged values of RUSPI. The size of the coefficients decreased as the length of the lag in RUSPI increased.

Cross spectral analysis was used to determine the extent to which cycles in the two data series (WABIX and RUSPI) interacted to support the relationship suggested by the Pearson correlation coefficient. As before, a firstdifference transformation was used to make the two data series stationary.

The squared coherency statistics for WABIX and RUSPI for frequencies or cycle lengths of approximately two months to 7.50 years per cycle were all 1.00 . Thus, on the basis of squared coherency it was possible to conclude that variation in WABIX and RUSPI was virtually identical regardless of cycle length.

With the exception of short cycles, i.e., less than 2.5 years in length, the gain statistic indicated that overall local economic activity as measured by WABIX was substantially more volatile than national economic activity as measured by RUSPI. As Santoni (1983) points out, that the local economy is more volatile than the national economy is not to be unexpected. Of interest, however, was the fact that the volatility of the local economy in comparison with the national economy increased with increases in cycle length. In turn, factors affecting the national economy, and thus the influence that the national economy has on the local economy, apparently have a stronger impact on the local economy over the longer run than over the shorter run. Additional evidence to support this conclusion was provided earlier when it was noted that, on balance, WABIX was flat during both the sixmonth 1980 national recession and the 18 -month 1981-82 national recession. Thus, based on data for the time period January 1979-July 1986, the local economy would appear to be relatively more stable during recessions than the national economy. This information has been very useful for public and private decision makers in the Wilmington area.

Based on the absolute values of the phase statistics, there wasno evidence of a lead or lag relationship for those cycles that were approximately $\mathbf{1 5 . 5}$ months or longer in duration. For short cycles, i.e., less than $\mathbf{1 5 . 5}$ months in length, the results were mixed.

In summary, the major findings from this comparison of the cycling of the local and national economies was that the local and national economies moved in tandem but that the local economy was relatively more stable during recessions than the national economy.

\section{Forecasting With National Indicators}

The coincident relationship between the local and national economies supplies a rationale for using the U.S. Department of Commerce's composite index of leading economic indicators (CILE) as a device for forecasting future turning points in local economic activity. Pearson correlation coefficients between WABIX and lagged values of CILE were calculated. The largest $(0.9096)$ was that between WABIX and CILE $E_{1.2}$ and was significant at the 0.0001 level. Over the time period January 1979-July 1986, CILE correctly anticipated turning points in WABIX two months later approximately 50 percent of the time. This forecasting success was no better than that expected from a white noise random variable.

\section{Summary}

Local economic conditions are frequently difficult to track and forecast because of deficient and irregularly reported data. Yet the decade of the 1980s has thus far been a time period characterized by a growing need of private and public decision makers for such information.

The purpose of this article has been to provide additional insight into a methodology for analyzing local economic conditions. It has focused on a local economy's current state and its expected state in the near future. Factor analysis was used to develop local coincident and leading indexes. Correlation and cross spectral analyses were used to examine the relationships between these local indexes and indexes of national economic activity 
with the intent of uncovering such useful information as the stability of the local economy relative to the national economy during recession periods.

It is hoped that the methodology presented in this article will add to the growing body of regional economic analysis such as the use of vector autoregressive models (Anderson, 1979; Cargill and Morris, 1986; Webb, 1984), to eventually provide breadth of coverage at the local level that is comparable to that at the national level.

\section{REFERENCES}

Anderson, Paul A. "Help for the Regional Forecaster. Vector Autoregression." Quarterly Review. Federal Reserve Bank of Minneapolis. (Summer 1979). 2-7.

Cargill, Thomas F. and Steven A. Morris. "Forecasting Nevada's Economy." FRBSF Weekly Letter. Federal Reserve Bank of San Francisco. (September 19, 1986).

Carlino, Gerald A. "Declining City Productivity and the Growth of Rural Regions." Journal of Urban Economics. 18 (1985). 11-27.

Conte, Michael A. "Leading Indicators for the New Orleans Metro Economy." Louisiana Business Survey. 17 (Spring 1986). 3-7.

Fishman, George S. Spectral Methods in Econometrics. Cambridge: Harvard University Press, 1969.
George, Edward. "New Economic Indicators for El Paso." Southwest Business and Economic Review. 2 (1980). 1-44.

Nathan, R. P. and F. C. Doolittle. "The Untold Story of Reagan's 'New Federalism.' " The Public Inter est. 77 (Fall 1984). 96-105.

Priestly, M. B. Spectral Analysis and Time Series - Volume 1: Univariate Series; Volume 2: Multivariate Series, Prediction and Control. New York: Academic Press, 1981.

Rati, Ronald A. "A Descriptive Analysis of Economic Indicators." Review. Federal Reserve Bank of St. Louis. (January 1985). 14-23.

Santoni, G. J. "The Relative Performance of the District and the Law of Large Numbers." Review. Federal Reserve Bank of St. Louis. 65 (December 1983). 19.

Webb, Roy H. "Vector Autoregression as a Tool for Forecast Evaluation." Economic Review. Federal Reserve Bank of Richmond. 70 (January/February 1984). 3-11.

Wheat, Leonard F. "The Determinants of 1963-77 Regional Manufacturing Growth: Why the South and West Grow." Journal of Regional Science. 26 (November 1986). 635659.

Zamowitz, Victor and Charlotte Boschan. "Cylical Indicators: An Evaluation and New Leading Economic Indicators." Business Conditions Digest. V-XI (May 1975). 